\title{
Do Excessive Wage Increases Raise Imports? Theory and Evidence
}

\author{
Jim Malley \\ Thomas Moutos \\ December 2000 \\ (this version February 2001)
}

\begin{abstract}
:
This paper uses a model of trade in vertically differentiated products to examine the effects of "excessive wage" increases (i.e. above productivity) on the volume of commodity imports. The model predicts that for commodities, in which the country has comparative advantage in high quality varieties, an increase in "excessive wages" may result in a decrease in the volume of imports. The empirical validity of the model's predictions is demonstrated with the use of disaggregated Japanese import data for the period 1967-95. We also find that the aggregate volume of Japanese imports is not responsive to "excessive wage" changes.
\end{abstract}

\section{JEL Classification: F4, F41}

Acknowledgements: We wish to thank Hassan Molana, Apostolis Philippopoulos and Ulrich Woitek for helpful comments. The usual disclaimer applies.

Jim Malley, Department of Economics, University of Glasgow, Glasgow G12 8RT, UK, email: j.malley@ socsci.gla.ac.uk (corresponding author).

Thomas Moutos, DIEES, Athens University of Economics \& Business, Patission 76, Athens 10434, Greece, email: tmoutos@ aueb.gr. 


\section{Introduction}

According to received wisdom, the effects of an increase in a country's real wage - ceteris paribus - on the volume of its imports are unambiguous. Since wage costs are part of total production costs, the price of domestically produced goods will increase relative to the price of imported goods, thereby increasing domestic demand for foreign produced goods and the volume of imports. This prediction of open economy macroeconomic models is the cornerstone of almost all applied trade balance analysis (see, for example, Hooper and Marquez (1995) and Krugman (1995)). In the present paper we argue that this prediction is not generally valid. To this effect we construct a model in which the volume of imports may not change (or even decline) in response to a rise in the real wage. The empirical validity of our theoretical arguments is then demonstrated with the use of disaggregated Japanese import data for the period 1967-95.

It is clear that a model with such a property must depart from the mainstream in some significant fashion ${ }^{1}$. The key assumption made here is that the goods, which the domestic country trades with the (ROW), are vertically differentiated according to quality $^{2}$. The domestic country is assumed to have absolute advantage at all quality levels and comparative advantage (CA) at high quality varieties $j$. In other words, we assume that the domestic country is technologically advanced. An increase - ceteris

\footnotetext{
${ }^{1}$ We identify the "imperfect - substitutes" model as the mainstream. In this model the domestic economy is assumed to specialize in the production of a single homogeneous good, which is an imperfect substitute for the single homogeneous good produced in the rest of the world. Obviously, this is the type of production structure underlying the Mundell-Fleming model.

${ }^{2}$ There is a considerable body of evidence which testifies to the importance of vertical intra-industry trade (see, for example, Greenaway and Torstensson (1999) and Durkin and Krygier (2000)). Greenaway and Torstensson conclude that for Sweden and the U.K. vertical intra-industry trade is quantitatively more important than horizontal intra-industry trade, whereas Durkin and Krygier conclude that about 70 percent of US intra-industry trade with OECD countries is vertically differentiated.
} 
paribus - in domestic wages will obviously reduce the range of qualities (varieties) which can be produced at lower cost by domestic producers. This, of course, implies the orthodox conclusion that - ceteris paribus - the volume of domestic imports will increase. But this is only half of the story because the increase in domestic wages (and hence - as explained later - household incomes) induces domestic consumers to switch their demand to higher quality varieties; i.e. to varieties in which the domestic country has a CA. It is thus possible that the latter effect largely offsets (or even overcomes) the traditionally expected one, so that the switch in demand to higher quality varieties results in no noticeable effect (or even a decline) in the volume of imports.

Although the theoretical result derived in this paper is novel, the idea that household income determines the quality of goods demanded is old. BurenstamLinder (1961) drew a sharp distinction between trade in primary products and trade in manufacturing goods. For primary products he argued that trade would be determined on the basis of factor endowments. For quality-differentiated manufacturing goods he argued that factor intensities were similar and that the principal determinant of the pattern of trade was the level of per-capita income. According to Burenstam-Linder, higher per-capita income induces consumers to demand not only more units of a given quality, but higher quality varieties as well. Flam and Helpman (1987) have provided a formalization of Burenstam-Linder's idea in the context of a North-South trade model $^{3}$. The present paper draws upon their specification of technology and preferences with one important exception. Flam and Helpman assume that labor is the only factor of production. When this assumption is coupled with the assumption

\footnotetext{
3 Other models of trade in vertically differentiated products include Falvey (1981), Eaton and Kierzkowski (1984), Shaked and Sutton (1984), Markusen (1986) and Stokey (1991).
} 
of constant returns and perfect competition, it implies that the real wage rate is constant and independent of the level of nominal wages - it depends only on productivity. In contrast, we assume that production cannot take place without the use of imported intermediate inputs. This implies that for any given price of the intermediate inputs (which is determined in the ROW), increases in nominal wage rates are no longer associated with constant real wages (and hence - as will become apparent later - household incomes). The resulting increase in (real) household incomes can thus effect the switch in demand from lower to higher quality varieties identified earlier.

The theoretical possibility that increases in real wages may not lead to an increase in the volume of imports necessitates an empirical examination of the issue. Nevertheless, it is obvious that the ceteris paribus proviso on which the theoretical analysis is based should not be ignored. If, for example, real wage increases did not keep pace with productivity increases, then nobody would be surprised to find a negative relationship between real wages and the volume of imports. On the other hand, if real wages increased at a faster rate than productivity (i.e. real wage increases were "excessive"), standard theory would predict a positive association between real wages and the volume of imports. For this reason in our empirical analysis, we enquire into the relationship between the volume of imports and (real) wages changes

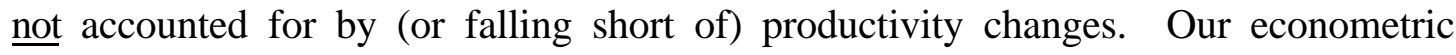
findings based on annual data for Japanese imports of 68 commodity groups provide considerable support for our theoretical framework of a technologically advanced country. We find that real wage changes not accounted for by productivity changes exert a (statistically) significant and positive influence on the volume of imports for only 28 of the commodity groups, whereas they exert a significantly negative 
influence for 10 of them, with the influence on the remaining 30 commodities being insignificant. Having established the empirical relevance of our theoretical framework at a disaggregated level we proceed to enquire about its macroeconomic importance. To this effect, we simulate for each commodity group the effects of a one-percentage-point increase in "excessive wages" on the volume of imports and then aggregate the responses. We find that the aggregate volume of imports does not respond to changes in "excessive wages".

The outline for the remainder of the paper is as follows. In Section 2 we set up our model of trade in vertically differentiated products and demonstrate how it is possible for a - ceteris paribus - increase in wages to results in a reduction in the volume of imports. In Section 3 we use Japanese data to enquire into the empirical importance of our theoretical statement. Our conclusions are then presented in Section 4 .

\section{The Model and its Implications}

\subsection{The Basic Model}

We construct the simplest possible model capable of illustrating the main idea of the paper. Given that our objective is the study of the partial equilibrium effects of wage rate changes on the volume of imports, we treat domestic (and ROW) nominal wages as exogenous.

\subsubsection{Technology}

We start by assuming that there are two goods produced in the domestic country: a homogeneous non-traded good and a quality-differentiated product which 
is traded with the ROW ${ }^{4}$. The ROW is also assumed to produce the differentiated product, albeit with a different technology. The homogeneous good $H$ is produced under perfectly competitive conditions in the domestic country, with the use of labour $L$, and imported intermediate inputs $S$ (e.g. oil). For the purpose of simplicity, we assume that the homogeneous good is produced with Leontief technology ${ }^{5}$ :

$$
H=\min \{\beta L, \beta S\}
$$

Perfect competition ensures that

$$
P_{H}=\left(W+P_{S}\right) / \beta
$$

where $P_{H}$ is the price of the homogeneous good, $W$ is the (domestic) wage rate, $P_{S}$ is the domestic price of the imported intermediate input and $\beta$ is a positive parameter.

The quality-differentiated good is also produced under perfectly competitive conditions $^{6}$. We assume that quality is measured by an index $Q$ in the range $[1, \infty]$, and that there is complete information regarding the quality index. We further assume that in both the domestic country and the ROW costs depend on quality, and that each unit of a given quality is produced at constant cost. That is, the production function for the quality-differentiated good in the domestic country is

$$
Y_{Q}=\min \left\{\frac{L}{\gamma Q^{\varepsilon}}, \frac{S}{\gamma Q^{\varepsilon}}\right\}, \varepsilon \geq 1, \gamma>0
$$

where $Y_{Q}$ denotes the number of units of quality $Q$ produced in the domestic country and $\varepsilon$ and $\gamma$ are constant parameters. The above equation implies that although costs per unit in terms of quantity are constant, costs may be increasing per unit of the

\footnotetext{
${ }^{4}$ In contrast, Flam and Helpman (op cit.) assume that both goods are traded.

${ }^{5}$ Schmid (1976) and Findlay and Rodriquez (1977) were the first to employ this assumption in openeconomy macroeconomics.

${ }^{6}$ Greenaway, Hine and Milner (1995) present evidence, which suggests that models with a large numbers of firms explain better the presence of vertical intra-industry trade.
} 
quality index. The latter assumption is motivated by the fact that increases in quality for a given state of technological capability - involve the "sacrifice" of an increasing number of personnel. These workers must be allocated not only to the production of a higher number of features attached to each good (e.g. electric windows, air bags, ABS etc. in the case of automobiles) that directly absorb labour and intermediate inputs, but also to the development and refinement of these features. According to equation (3), the price at which each unit of quality $Q$ will be offered is equal to

$$
P(Q)=\gamma Q^{\varepsilon}\left(W+P_{S}\right) .
$$

The domestic country is assumed to have absolute advantage in the production of the quality-differentiated good, and this advantage becomes larger as the quality index increases. This assumption can be captured by writing the production function for the ROW (we denote variables pertaining to the ROW by an asterisk),

$$
Y_{Q}^{*}=\min \left\{\frac{L^{*}}{\delta Q^{\mu}}, \frac{S}{\delta Q^{\mu}}\right\}, \delta>0, \mu>1, \mu>\varepsilon, \delta>\gamma .
$$

According to equation (5), the price at which each unit of quality $Q$, will be offered by ROW producers is equal to

$$
P^{*}(Q)=\delta Q^{\mu}\left(W^{*}+P_{S}\right)
$$

Under these circumstances it is obvious that only if domestic wages are higher than ROW wages, will the ROW be able to produce some varieties (qualities) at a lower cost than the domestic country. Figure 1 illustrates such a case.

The schedule $C\left(W_{0}\right)$ represents the cost of producing different qualities of the differentiated good in the domestic country. The position of the schedule obviously depends on domestic wages which are initially assumed to be $W_{0}$. For the ROW, the corresponding schedule is $C^{*}\left(W^{*}\right)$ with $W^{*}<W_{0}$. Under this particular structure of 
wages, the ROW will be offering all qualities up to $Q_{D, 0}$ at a lower cost than the domestic country. We term $Q_{D, 0}$ the "dividing" level of quality. All varieties with quality larger than $Q_{D, 0}$ will be offered by domestic producers. From Figure 1 it is obvious that the domestic country can increase the range of varieties which it can produce at lower cost than the ROW, if the wage rate is reduced to $W_{l}$. The new dividing level of quality is now $Q_{D, 1}$. This reduction in the range of varieties, which the ROW can provide at lower cost, is traditionally always expected to result in a reduction of domestic imports.

Figure 1: The relationship between quality and cost

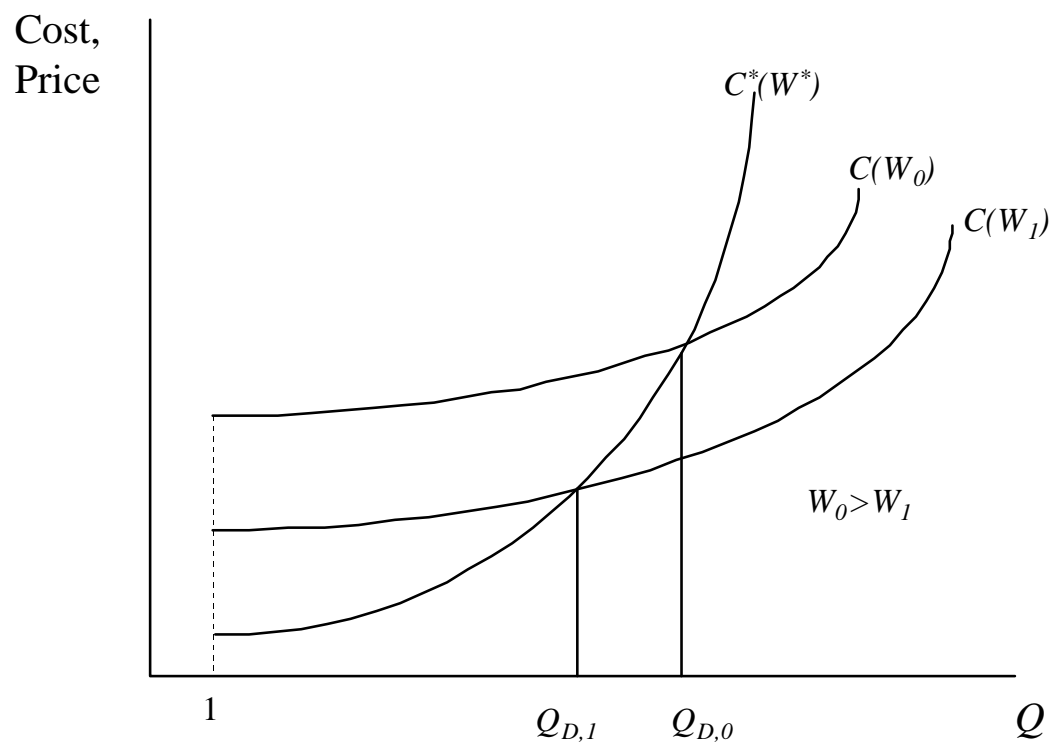

\subsubsection{Preferences}

Households in both the domestic country and the ROW are assumed to have identical preferences, and to be endowed with one unit of labour, which they offer inelastically. In this sense, changes in the real wage rate produce equiproportional change in household income and total compensation per employee. There are however, differences in skill between households (both within and across regions) which are reflected in differences in the endowment of effective labour supply. This 
$\mathrm{P}(\mathrm{Q}) / \mathrm{Q})$ which the consumer pays for the differentiated good is not constant.

Nevertheless, the household knows the exact correspondence between quality and 
price, as both the domestic and the ROW firms are assumed to announce to households a price list linking quality to price according to equations (4) and (6). Equation (8) implies that the budget constraint is non-differentiable at the "dividing" level of quality $Q_{D}$ (see Figure 1), i.e. the quality level at which the cost of production is the same in the domestic country and the ROW.

\section{Figure 2: Incomes and Choice of Consumption}

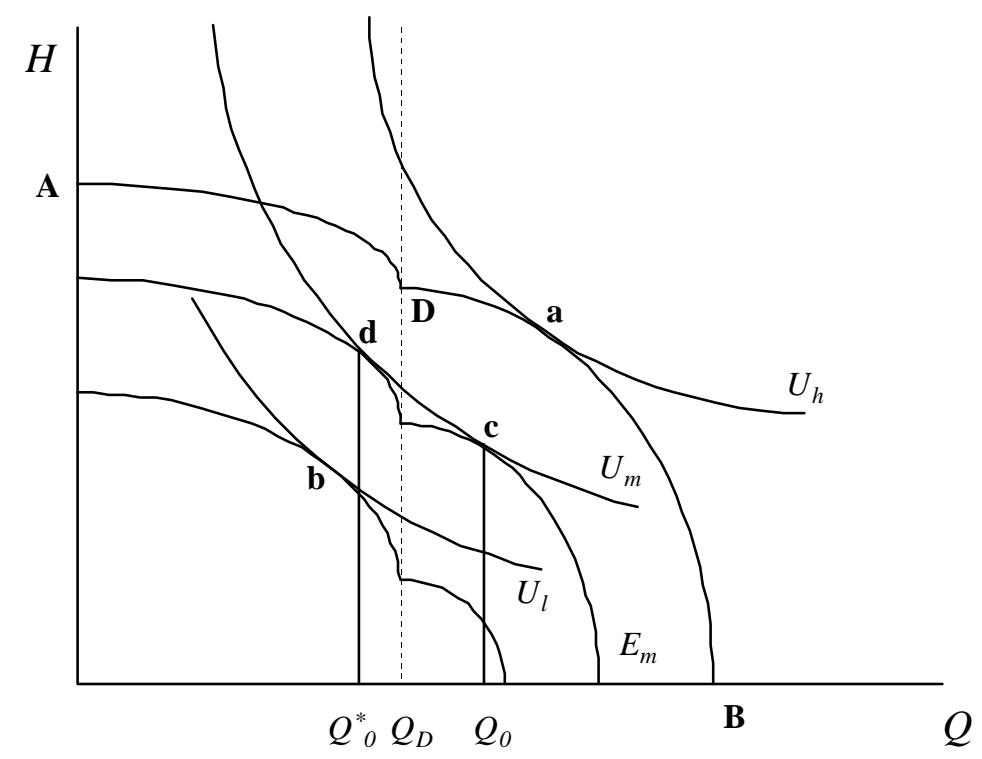

In Figure 2, the budget constraint for a high-income household is shown as the curve ADB. Points $\mathbf{A}$ and $\mathbf{B}$ denote the maximum quantity and quality of the homogenous and the differentiated good, respectively, that a high-income household can buy ${ }^{7}$. The budget constraint is discontinuous at point $\mathbf{D}$, which corresponds to the “dividing" level of quality $Q_{D}$. It is then possible that there may be an income (say $\left.E_{m}\right)$ such that the household is indifferent between buying the ROW produced quality $Q_{0}^{*}$ and the domestically produced quality $Q_{0}$. It is also clear that in this case that there will be no demand for qualities in the range $\left(Q_{0}^{*}, Q_{0}\right)$. Further consideration of

\footnotetext{
${ }^{7}$ The horizontal axis has been properly re-labeled to reflect the assumption that the differentiated good is not offered at qualities $\mathrm{Q}<1$.
} 
such a situation presents no new insights for the analysis that follows. It is for this reason that we assume incomes of all classes to be such that consumers have a clear preference for either domestic or ROW varieties. This is also demonstrated in Figure 2, in which the low income household is shown to maximize its utility by consuming an imported variety (point b), whereas the high income household achieves it highest utility level by consuming a domestic produced variety (point a).

\subsubsection{Real Wages and Imports}

The effects of an increase in the real wage rate on the (volume of) imports depend heavily on the specification of the initial equilibrium. We start by considering the case in which the domestically produced variety is consumed initially only by the high and the middle-income households in the domestic country. In Figures $3 a-3 c$ the initial equilibrium is displayed by the tangency of the budget constraints and the indifference curves at point $\mathbf{0}$.

Consider now an increase in domestic wages. Given perfect competition, all income accruing to domestic households consists of wages. This implies that the budget constraint moves outwards for all three-income groups. This happens because the prices of both the homogeneous good and the quality differentiated good rise less than proportionately to the wage rate. The assumption of an exogenous price for the imported intermediate input is thus crucial for connecting nominal wage decreases to a decline in real income. Along with the rise in domestic real income there is a decrease in the range of qualities (varieties) of the differentiated good which the domestic country can offer at a lower cost than the ROW. In Figure 3a, the rise in domestic wages is associated with a shift of consumption for the low-income domestic households from lower to higher quality ROW produced goods. In Figure 
Figure 3: Real Wage Changes and Imports

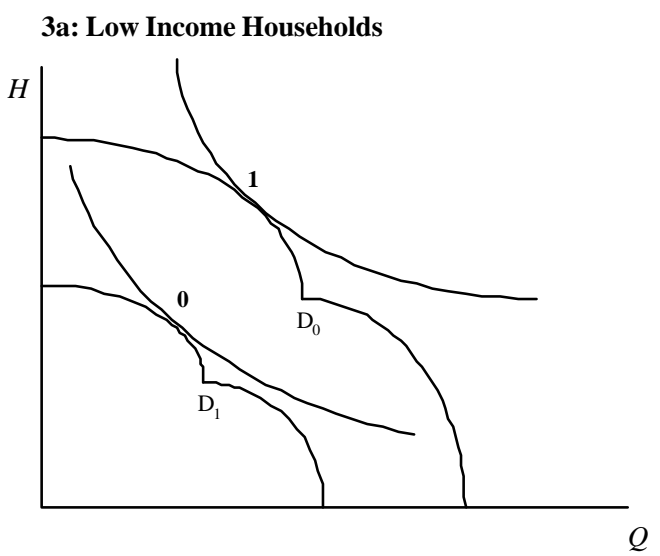

3b: Middle Income Households

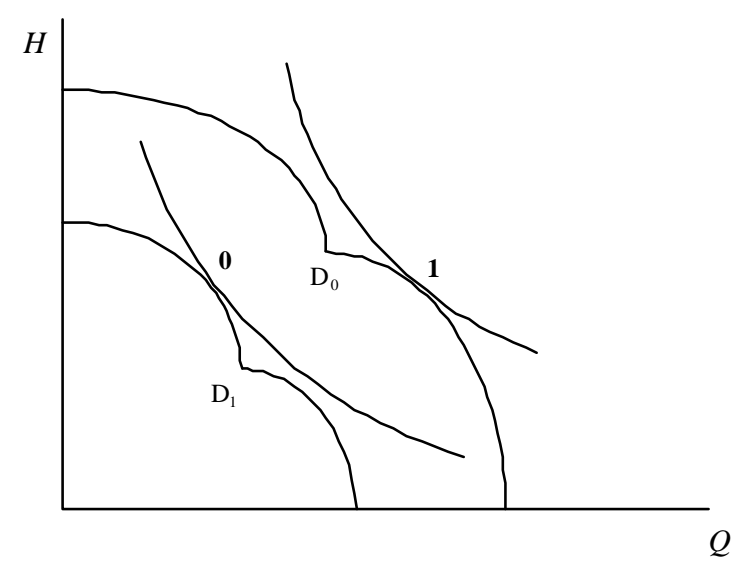

3c: High Income Households

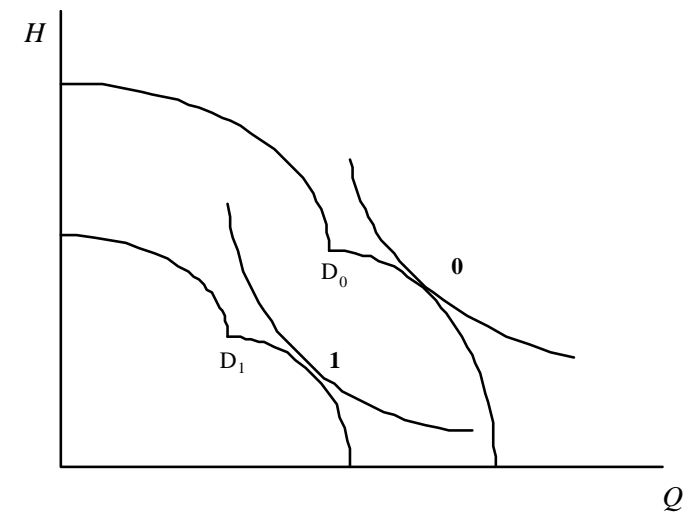


3c, as in Figure 3a, the increase in domestic wages does not switch demand from goods (varieties) produced in one region to another. It only leads domestic consumers to demand higher quality (domestically produced) varieties than before.

In Figure 3b, the increase in domestic wages is associated with a switch in the consumption pattern of the middle-income domestic consumers. The increase in their real income induces them to substitute higher quality domestically produced goods for the lower-quality ROW produced goods they were demanding before. This switch will decrease the volume of domestic imports. The increase in domestic wages could obviously lead to a shift from lower to higher quality domestically produced goods, without a corresponding decrease in imports. But in any case, the traditional expected increase in the volume of imports would not be observed.

What Figures 3a-3c make clear is that, the volume of domestic imports may well decrease following an increase in domestic wages (incomes). The precise effect will obviously depend on the size of the three income groups. The larger the middleincome group, the larger will be the expected decrease in domestic imports since this is the group for which the increase in real income may result in a switch from varieties produced in the ROW to domestically produced varieties. The reason behind this unexpected result is that an increase in domestic wages even though it makes the home country less competitive, it induces domestic consumers to switch their demand to higher quality goods. But these are precisely the goods in which the domestic country has a CA. This latter effect has hitherto been ignored. The typical analysis of the effects of wage changes concentrates only on cost competitiveness, and it ignores the resulting switch in demand to varieties in which the domestic country has a CA. 
It must, however, be noted that the effects on the "total volume" of imports of differentiated goods resulting from an increase in domestic wages is more complicated. Notice (as shown in Figure 3a), that the low-income group still consumes varieties produced in the ROW after the increase in domestic wages. But these imports are now of a higher quality than before. In some sense, the "total volume" of imports by this group increases ${ }^{8}$. It is thus possible (even for the special case presented in Figure 3) that, despite the switch depicted in Figure 3b, the aggregate "volume" of imports responds in the traditional manner following a increase in domestic wages.

The reasons for this unexpected result can be better appreciated if we conceptually divide the shift from point $\mathbf{0}$ to point $\mathbf{1}$ in Figure $3 \mathrm{~b}$ into two separate effects. The first effect is the traditional influence of wages on costs. An increase in domestic wages makes the home country even less competitive in the qualities (varieties) in which it already was less competitive than the ROW and it contracts the range of qualities, which the domestic country produces at a lower cost. We term this effect, the "cost effect". The second effect arises from the influence that wages have on household income and hence on spending patterns. An increase in the wage rate results in higher household income, and a switch of demand to higher quality varieties. But, these are precisely the varieties in which the domestic country has a CA. This second effect has hitherto been ignored. We term this, the "income effect". The typical analysis of the effects of wage changes concentrates only on cost competitiveness (the "cost effect"), and it ignores the resulting switch in demand

\footnotetext{
${ }^{8}$ Even though we will repeatedly use the term "total volume" of imports we do not include imported intermediate inputs in this measure. Given our assumptions, the volume of these intermediate inputs is directly related to both the "volume" and "quality" of domestically produced products. Any conclusions we derive pertain thus to final goods imports alone. We discuss this issue further in the following section.
} 
towards varieties in which the domestic country has a CA (the "income effect") ${ }^{9}$. It is the purpose of the empirical analysis, which follows to examine which of these two effects, predominates.

It should be noted that, of course, there is no country in the world, which has CA in high quality varieties for all the commodities that it trades with the ROW. In the case of commodities for which the domestic country's CA is in low quality varieties, our analysis predicts - in common with standard theory - that a - ceteris paribus - increase in domestic wages will result in an increase in the volume of imports. Moreover countries trade not only in differentiated products, but in homogeneous goods as well. For this reason we have chosen Japan as the country on which to conduct our empirical analysis, since Japan's international trade is probably the most technology (rather than endowment) driven than any country in the world. Dosi, Pavitt and Soete (1990), for example, report that in 1986 Japan was the major foreign country patenting in the United States, accounting for more than 40 percent of total US patents of foreign origin (Germany's share stood at just over 20 percent).

\section{Empirical Implications and Evidence}

In this section we develop and test the main empirical implication of the theory developed in Section 2. As explained, our model predicts that real wage changes have an ambiguous effect on the volume of imports. Nevertheless, the ceteris paribus - wage change assumed in our theoretical analysis surely finds no match in the data of any real economy. The actual real wage data certainly reflect labour productivity changes, in which case costs may not rise is response to real wage

\footnotetext{
${ }^{9}$ The "income effect" identified in this paper must be distinguished from the traditional inclusion of an aggregate activity variable (GDP for example) in import demand equations. We discuss this issue further in the following Section.
} 
$\left.w^{e}\right)$, and we obtain it from the residuals of a regression of the natural logarithm of real compensation per employee $(w)$ on the natural logarithm of an index of productivity $(p)$, i.e.

$w^{e}=w-w^{*}=w-\delta-\phi p$

where $w^{*}$ is the part of $w$ directly attributable to productivity. According to received wisdom, an increase in $w^{e}$ is expected to increase the volume of imports.

In addition to the "excess wage" variable, we include two other "traditional" explanatory variables for the volume of imports in our econometric investigation: an aggregate activity variable and the price of imported goods ${ }^{10}$. The inclusion of an aggregate activity variable in our framework is essential for two reasons. First, note that in our theoretical analysis labour is assumed to be the only domestically owned factor of production. Nevertheless, since household consumption choices are made on the basis of total household income, rather than income derived from the sale of the household's labour services alone, care must be taken to control for the other sources of income. Second, the presence of not only final consumption goods but of intermediate inputs as well in the actual import data necessitates the inclusion of a variable measuring aggregate domestic activity. We use domestic GDP to control for the influence of the above concerns. Changes in the prices of imported goods (resulting from changes in exchange rates, foreign wages, foreign productivity, etc.) can also affect the "dividing" quality level and the volume of imports. We control for these (independent of the behavior of domestic wages) changes in competitiveness by

\footnotetext{
10 These two variables are standard ones used in the empirical literature on import demand. See Goldstein and Khan (1984) for a thorough discussion of specification issues.
} 
include the price of imported goods (expressed in domestic currency (i.e. yen)) in the econometric estimation. Note that had we included the ratio of domestically produced to imported goods prices (i.e. the terms of trade) as an independent variable instead of just the prices of imported goods, the estimated coefficient of the "excessive wages" variable would measure only (what we termed in the previous Section) the "income effect". Since we want to investigate whether the "income" or the "cost" effects of "excessive wages" changes predominate, we control for only those changes in competitiveness, which are independent of the behavior of domestic wages. This issue is discussed further in the following pages.

Our regression analysis is conducted with Japanese annual data from the period 1967-95 for sixty-eight commodity groups. These data are obtained from the CHELEM (Harmonized Data for International Trade and the World Economy) and the OECD (Annual National Accounts and Economic Outlook) databases ${ }^{11}$. We begin by estimating the relationship between real commodity imports and the real "excess wage" per employee, controlling for aggregate income, competitiveness and deterministic trends, e.g.

$m_{i}=w^{e} \alpha+\mathbf{X} \beta+\mathbf{D} \gamma+\varepsilon ; \quad \varepsilon \sim \operatorname{iid}\left(0, \sigma^{2} \mathbf{I}\right) ; \quad \operatorname{cov}(z, \varepsilon)=0=\operatorname{cov}(\mathbf{X}, \varepsilon)$,

where $m_{i}$ is the vector of real imports for the $i^{\text {th }}$ commodity $(i=1, \ldots, 68) ; w^{e}$ is the excess wage vector ${ }^{12}, \mathbf{X}$ is a matrix of stochastic control variables $\left[y, m_{p}\right] ; y$ is real GDP and $m_{p}$ is the yen price of imports; and $\mathbf{D}$ is a matrix of deterministic

\footnotetext{
${ }^{11}$ Note that commodity \#57 (electricity) reported in Table 2 below is excluded from the analysis since it is not reported in CHELEM. See the Data Appendix for further details on variable definitions, sources and methods.

12 Both Pudney (1982) and Pagan (1984) have shown that the two-step estimator of (10) is consistent as long as $\operatorname{cov}(\mathbf{X}, \varepsilon)=\operatorname{cov}(z, \varepsilon)=0$. We will examine the validity of this assumption using the Durbin$\mathrm{Wu}$-Hausman test.
} 
components containing a constant term and linear and quadratic trends. Lower case letters for the variables denote natural logarithms.

Given our concentration on hypothesis testing, we would like to ensure that (10) is not spurious and further that our stochastic conditioning variables, i.e. the generated regressor, $w^{e}$, and the control variables $y$ and $c$, are not correlated with the errors. To address the former we apply a modified von Neumann type ratio test to the errors in specification (10). For example, we test for stationarity of the errors using the Bhargava (1986) statistic, e.g.

$$
R_{1}=\sum_{t=2}^{T}\left(\hat{\varepsilon}_{t}-\hat{\varepsilon}_{t-1}\right)^{2} / \sum_{t=1}^{T}\left(\hat{\varepsilon}_{t}-\overline{\hat{\varepsilon}}\right)^{2}
$$

where $\hat{\varepsilon}$ is the equation residual. The statistic $R_{l}$ is used to test the null of a simple random walk, (i.e. $\Delta \hat{\varepsilon}_{t}=e_{t}$, where, $\hat{\varepsilon_{1}}=\mu+e_{1}, t=2, \ldots T$ ) against the stationary alternative $\left(\hat{\varepsilon}_{t}-\mu\right)=\left(\hat{\varepsilon}_{t-1}-\mu\right)+e_{t}$, where $\left.\hat{\varepsilon}_{1}=\mu+\left[e_{1} /\left(1-\rho^{2}\right)^{1 / 2}\right], \quad \mathrm{t}=2, \ldots, \mathrm{T}, \quad 0 \leq \rho<1\right)$. Applying this test we find that the errors in virtually all commodity equations are stationary. The exceptions include industries 20 and 36, i.e. watch \& clockmaking and vehicle components respectively. These results are summarised in Figure 4,

Figure 4 - Stationarity Test for all Import Equations

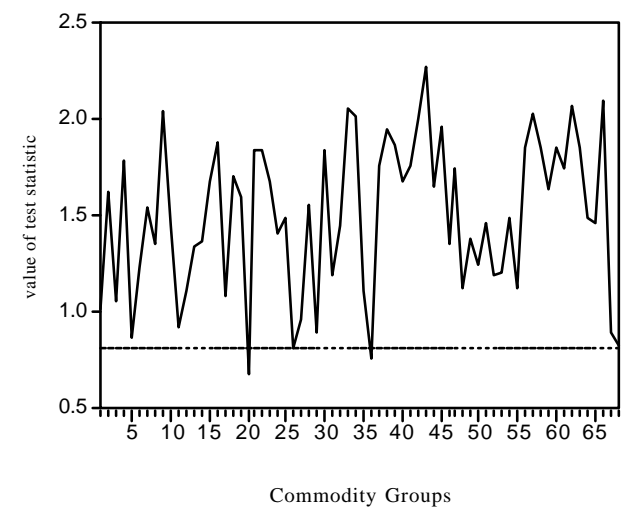


where the vertical axis represents the value of the $R_{l}$ test statistic and the horizontal the sixty-eight commodity groups. Finally, the horizontal line in Figure 4 is the exact limit at $5 \%$ for $R_{l}, N=29$ (i.e. 0.814$)^{13}$.

With respect to the issue of potential correlation between the conditions variables we compare $O L S$, which is efficient (or more efficient) under the null but inconsistent under the alternative, with the $I V$ estimator, which is consistent (and less efficient) under both hypotheses. For example, the Durbin-Wu-Hausman (DWH) test (see Hausman (1978)) is calculated as follows:

$D W H=\left(b_{O L S}-b_{I V}\right)^{\prime}\left(\mathbf{S}_{O L S}-\mathbf{S}_{I V}\right)^{-1}\left(b_{O L S}-b_{I V}\right) \sim \chi^{2}(k)$,

where $\mathrm{b}_{O L S}, \mathrm{~b}_{I V}$ are the vectors of estimated parameters of $O L S$ and $I V$ respectively, $\mathbf{S}_{O L S}, \mathbf{S}_{I V}$ are the estimated variance covariance matrices of $O L S$ and $I V$ respectively and $k$ refers to the degrees of freedom which are equal to the rank of $\left(\mathbf{S}_{O L S}-\mathbf{S}_{I V}\right)^{14}$. Applying this test we find that in none of the 68 cases, do the $O L S$ estimates significantly differ from the $I V$ estimates. These results are summarized in Figure 5, where the vertical axis represents the value

Figure 5 - DWH Test for all Import Equations

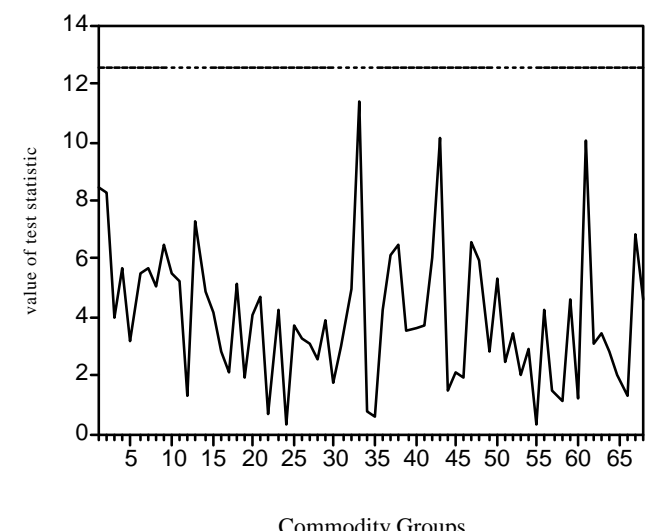

\footnotetext{
${ }^{13}$ This value is found by interpolation using Table 1 in Bhargava (op cit).

${ }^{14}$ Note that the parameter vector $b$ includes $\hat{\alpha}$ and the $\hat{\beta}$ and $\hat{\gamma}$ vectors. Also note, in addition to all the deterministic components in (10), that the instrument set includes a one-year lag of each conditioning variable.
} 
of the DWH test statistic and the horizontal the sixty-eight commodity groups.

Finally, the horizontal line in Figure 5 is the critical value of the $\chi^{2}$ distribution at $k=6$ (i.e. 12.59).

Next we report a summary of the $O L S$ parameter estimates of (10) in both Figure 6 and Table 1. Figure 6 contains a frequency distribution for $\alpha$ and for each element of the parameter vector $\beta$ (except for commodity groups 20,36 - for which the errors were non-stationary) and 57 (for which no data are available). As can be seen from Table 1, for the majority of commodity groups the estimates of the GDP coefficient and the import prices coefficient are consistent with standard theoretical priors. In the case of GDP, for about seventy percent of the commodity groups (46 out of 66) the coefficient is positive, whereas for the rest of the commodity groups the coefficient is (statistically) not different from zero. In the case of import prices, for

\section{Figure 6 - Distributions for OLS Parameter Estimates}
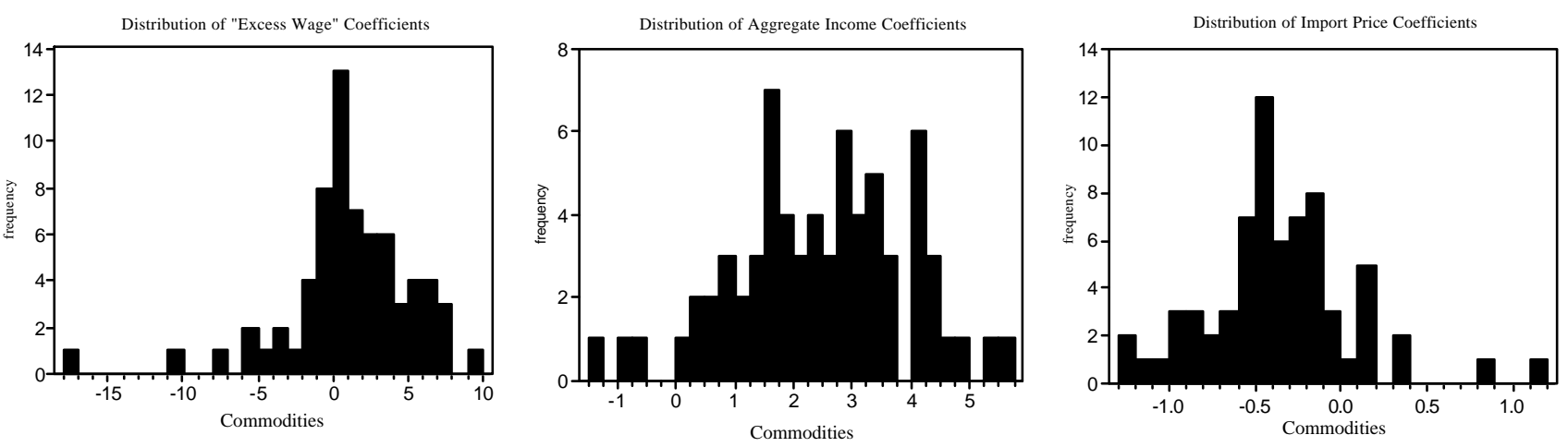

Table 1: Summary Statistics for the Distributions of $O L S$ Parameter Estimates

\begin{tabular}{|lr|lr|lr|}
\hline \multicolumn{2}{|c|}{$\partial m_{i} / \partial w^{e}=\hat{\alpha}_{i}$} & \multicolumn{2}{c|}{$\partial m_{i} / \partial y=\hat{\beta}_{1 i}$} & \multicolumn{2}{c|}{$\partial m_{i} / \partial m_{p}=\hat{\beta}_{2 i}$} \\
\hline Mean & 1.124 & Mean & 2.454 & Mean & -0.362 \\
Median & 1.111 & Median & 2.516 & Median & -0.397 \\
Std. Dev. & 4.249 & Std. Dev. & 1.469 & Std. Dev. & 0.433 \\
\# significantly (+) & 26 & \# significantly (+) & 46 & \# significantly (+) & 3 \\
\% significantly (+) & 0.394 & \% significantly (+) & 0.696 & \% significantly (+) & 0.045 \\
\# significantly (-) & 10 & \# significantly (-) & 0 & \# significantly (-) & 37 \\
\% significantly (-) & 0.152 & \% significantly (-) & 0.000 & \% significantly (-) & 0.560 \\
\hline
\end{tabular}


about fifty-six percent of the commodity groups (37 out of 66) the coefficient is negative, whereas there are 3 commodity groups for which the coefficient is positive. In contrast, for the majority of commodity groups (40 out of 66 ), the volume of imports is not positively affected by "excessive wages" $\left(w^{e}\right)$. In Table 2 we list all 66 commodity groups and note that for 10 groups the estimated value of $\alpha_{i}$ is negative and for 26 groups it is positive i.e. $w^{e}$ exerts a negative influence on the volume of imports.

Table 2: Commodity imports with significant (-) \& (+) response to changes in $w^{e}$

\begin{tabular}{|c|c|c|c|}
\hline 1 & Cement $\&$ derived products & 36 & Cars (inc. motorcycles) \\
\hline 2 & Ceramics (inc. manuf. Mineral articles) & 37 & Commercial vehicles \& transport equip. \\
\hline 3 & Glass (flatware \& hollow-ware) & 38 & Ships (inc. oil rigs) \\
\hline 4 & Iron \& steel (inc. pig iron \& sheet steel) & 39 & Aeronautics \\
\hline 5 & Tubes \& first stage processing products & 40 & Basic inorganic chemicals \\
\hline 6 & Non-ferrous metals & 41 & Fertilisers \\
\hline 7 & Yarns \& fabrics & 42 & Basic organic chemicals \\
\hline 8 & Clothing (with fabrics as the main input) & 43 & Paints, colourings \& inter. Chem. Products \\
\hline 9 & Knitwear (made directly from yarns) & 44 & Toilet products, soaps \& perfumes \\
\hline 10 & Carpets \& textile furnishings & 45 & Pharmaceuticals \\
\hline 11 & Leather furskins \& footwear & 46 & Plastics, fibers \& synthetic resins \\
\hline 12 & Articles in wood & 47 & Plastic articles \\
\hline 13 & $\begin{array}{l}\text { Furniture (made of wood or other } \\
\text { materials) }\end{array}$ & 48 & Rubber articles (inc. tyres) \\
\hline 14 & Paper \& pulp & 49 & Iron ores \& scrap \\
\hline 15 & Printing \& publications & 50 & Non-ferrous ores \& scrap \\
\hline 16 & $\begin{array}{l}\text { Toys, sports equip. \& misc. manuf. } \\
\text { Articles }\end{array}$ & 51 & Unprocessed minerals \\
\hline 17 & Large metallic structures & 52 & Coal (inc. lignite \& other prim. energy) \\
\hline 18 & Miscellaneous hardware & 53 & Crude oil \\
\hline 19 & Engines, turbines \& pumps & 54 & Natural gas (inc. all petroleum gases) \\
\hline 20 & Agricultural equipment & 55 & Coke \\
\hline 21 & Machine tools & 56 & Refined petroleum products \\
\hline 22 & Construction \& public works equipment & 57 & Electricity [not reported for Japan] \\
\hline 23 & Specialised machines & 58 & Cereals \\
\hline 24 & Arms \& weaponry & 59 & Other edible agricultural products \\
\hline 25 & Precision instruments & 60 & Non-edible agricultural products \\
\hline 26 & Watch \& clockmaking & 61 & Cereal products \\
\hline 27 & Optics \& photo- \& cinema-graphic equip. & 62 & Fats (of vegetable or animal origin) \\
\hline 28 & Electronic components & 63 & Meat and fish \\
\hline 29 & Consumer electronics & 64 & Preserved meat \& fish products \\
\hline 30 & Telecommunications equipment & 65 & Preserved fruit \& vegetable products \\
\hline 31 & Computer equip. (inc. office equip.) & 66 & Sugar products (inc. chocolate) \\
\hline 32 & Domestic electrical appliances & 67 & Animal products \\
\hline 33 & Heavy electrical equip. & 68 & Beverages \\
\hline 34 & Electrical apparatus (inc. passive devices) & 69 & Manufactured tobaccos \\
\hline 35 & Vehicle components & & \\
\hline
\end{tabular}

Note: significantly (-) commodities in are bold and (+) ones in italics. 
Figure 7 - Distributions for OLS Parameter Estimates

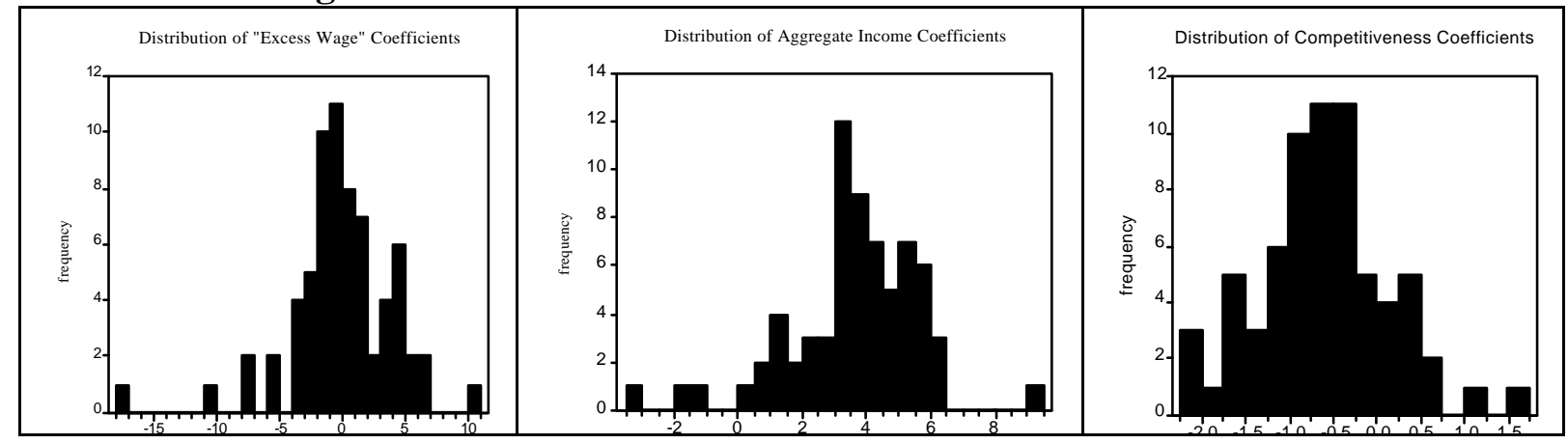

Table 3: Summary Statistics for the Distributions of $O L S$ Parameter Estimates

\begin{tabular}{|lr|lr|lr|}
\hline \multicolumn{2}{|c|}{$\partial m_{i} / \partial w^{e}=\hat{\alpha}_{i}$} & \multicolumn{2}{c|}{$\partial m_{i} / \partial y=\hat{\beta}_{1 i}$} & \multicolumn{2}{c|}{$\partial m_{i} / \partial c=\hat{\beta}_{2 i}$} \\
\hline Mean & -0.090 & Mean & 3.607 & Mean & -0.611 \\
Median & -0.387 & Median & 3.643 & Median & -0.637 \\
Std. Dev. & 4.073 & Std. Dev. & 2.012 & Std. Dev. & 0.747 \\
\# significantly (+) & 18 & \# significantly (+) & 61 & \# significantly (+) & 5 \\
\% significantly (+) & 0.273 & \% significantly (+) & 0.924 & \% significantly (+) & 0.075 \\
\# significantly (-) & 16 & \# significantly (-) & 2 & \# significantly (-) & 38 \\
\% significantly (-) & 0.242 & \% significantly (-) & 0.030 & \% significantly (-) & 0.576 \\
\hline
\end{tabular}

According to our theoretical framework, a positive $\hat{\alpha}_{i}$ implies that the "cost" effect dominates the "income" effect of "excessive wages". This will obviously be the case for homogenous products or for goods in which Japan's CA is in low quality varieties. On the other hand, a negative $\hat{\alpha}_{i}$ implies that the "income" effect dominates the "cost" effect, whereas for the remaining commodities the two effects appear to mostly cancel each other out. As a further test of our theoretical framework, in Figure 7 and Tables 3 and 4 we show the results of allowing "excessive wages" to affect the volume of imports only through the "income" effect. For this reason, we reestimate the import volume equations for the 66 commodity groups. In the new equations we use the relative price of imported to domestic goods (i.e. competitiveness) to restrict $w^{e}$ to affect the volume of imports only through the "income" effect. We note through comparison of Tables 1 and 3 that the number of commodity groups with a negative $\hat{\alpha}_{i}$ has increased to 16 (from 10), whereas the 
number of commodity groups with a positive $\hat{\alpha}_{i}$ has decreased to 18 (from 26). These changes are in agreement with our theoretical priors. We expect that when only the "income" effect is allowed to operate the number of commodity groups with a positive $\hat{\alpha}_{i}$ should decrease. Indeed, our estimation reveals that the set of commodity groups with a $\hat{\alpha}_{i}$ shrinks when only the "income" effect is operating, and - more importantly - it includes only these commodity groups for which $\hat{\alpha}_{i}$ is positive when both ("income" and "cost") effects are allowed to influence the volume of imports. In the same vein, we expect that when only the "income" effect is allowed to operate, the number of commodity groups with a negative $\hat{\alpha_{i}}$ will increase. Comparison of Tables 2 and 4 reveals this to be the case as well.

Given the existence of large differences in the response of the volume of imports to "excessive wages" across the different commodity groups, a natural question to ask is what is the net effect at the aggregate level? To answer this question we use the estimated equations for each commodity group to predict the effects of a one percentage-point increase in $w^{e}$ on the volume of imports. We then sum over the predicted change in the volume of imports for each commodity group. For example, we find that in response to a one percentage-point increase in $w^{e}$, the aggregate volume of imports is expected to increase by 0.01 percentage points. Additionally, this small net response of the aggregate volume of imports is found to be not (statistically) different from zero. The aggregate effects thus provide considerable support for our theoretical framework. 


\section{Table 4: Commodity imports with significant $(-) \&(+)$ response to changes in $w^{e}$}

\begin{tabular}{|c|c|c|c|}
\hline 1 & Cement $\&$ derived products & 36 & Cars (inc. motorcycles) \\
\hline 2 & Ceramics (inc. manuf. Mineral articles) & 37 & Commercial vehicles \& transport equip. \\
\hline 3 & Glass (flatware \& hollow-ware) & 38 & Ships (inc. oil rigs) \\
\hline 4 & Iron \& steel (inc. pig iron \& sheet steel) & 39 & Aeronautics \\
\hline 5 & Tubes \& first stage processing products & 40 & Basic inorganic chemicals \\
\hline 6 & Non-ferrous metals & 41 & Fertilisers \\
\hline 7 & Yarns \& fabrics & 42 & Basic organic chemicals \\
\hline 8 & Clothing (with fabrics as the main input) & 43 & Paints, colourings \& inter. Chem. Products \\
\hline 9 & Knitwear (made directly from yarns) & 44 & Toilet products, soaps \& perfumes \\
\hline 10 & Carpets \& textile furnishings & 45 & Pharmaceuticals \\
\hline 11 & Leather furskins \& footwear & 46 & Plastics, fibers \& synthetic resins \\
\hline 12 & Articles in wood & 47 & Plastic articles \\
\hline 13 & $\begin{array}{l}\text { Furniture (made of wood or other } \\
\text { materials) }\end{array}$ & 48 & Rubber articles (inc. tyres) \\
\hline 14 & Paper \& pulp & 49 & Iron ores \& scrap \\
\hline 15 & Printing \& publications & 50 & Non-ferrous ores \& scrap \\
\hline 16 & $\begin{array}{l}\text { Toys, sports equip. \& misc. manuf. } \\
\text { Articles }\end{array}$ & 51 & Unprocessed minerals \\
\hline 17 & Large metallic structures & 52 & Coal (inc. lignite \& other prim. energy) \\
\hline 18 & Miscellaneous hardware & 53 & Crude oil \\
\hline 19 & Engines, turbines \& pumps & 54 & Natural gas (inc. all petroleum gases) \\
\hline 20 & Agricultural equipment & 55 & Coke \\
\hline 21 & Machine tools & 56 & Refined petroleum products \\
\hline 22 & Construction \& public works equipment & 57 & Electricity [not reported for Japan] \\
\hline 23 & Specialised machines & 58 & Cereals \\
\hline 24 & Arms \& weaponry & 59 & Other edible agricultural products \\
\hline 25 & Precision instruments & 60 & Non-edible agricultural products \\
\hline 26 & Watch \& clockmaking & 61 & Cereal products \\
\hline 27 & Optics \& photo- \& cinema-graphic equip. & 62 & Fats (of vegetable or animal origin) \\
\hline 28 & Electronic components & 63 & Meat and fish \\
\hline 29 & Consumer electronics & 64 & Preserved meat \& fish products \\
\hline 30 & Telecommunications equipment & 65 & Preserved fruit \& vegetable products \\
\hline 31 & Computer equip. (inc. office equip.) & 66 & Sugar products (inc. chocolate) \\
\hline 32 & Domestic electrical appliances & 67 & Animal products \\
\hline 33 & Heavy electrical equip. & 68 & Beverages \\
\hline 34 & Electrical apparatus (inc. passive devices) & 69 & Manufactured tobaccos \\
\hline 35 & Vehicle components & & \\
\hline
\end{tabular}

Note: as in Table 2 the significantly (-) commodities in are boldand (+) ones in italics.

\section{Conclusions}

In this paper we presented a model of trade in vertically differentiated products. An important result emanating from the structure of this model is that a ceteris paribus - increase in the wage rate of a technologically advanced country many not lead to an increase in the volume of its imports. This prediction was supported by our analysis of Japanese imports of 66 commodity groups. We found that no only there exist some commodities, for which the volume of imports is 
negatively associated with domestic wages, but that the volume of aggregate imports does not respond to an increase in domestic wages.

An important topic for further research would be to use more finely disaggregated data to test some other hypotheses emanating from our theoretical framework. One such hypothesis concerns the impact of a change in a country's wage rate on the country of origin of its imports. A - ceteris paribus - increase in (for example) Japan's wage rate would be expected to increase the share of its imports originating from countries which have comparative advantage in high quality products - i.e. the share of Japanese imports originating from low income countries would be expected to decrease. If this is the case, then high growth rates in the industrialized world may prove to be detrimental for the exports of very low income countries. 


\section{References}

Bhargava, A., 1986, On the Theory of Testing for Unit Roots in Observed Time Series, Review of Economic Studies, 53, 369-384.

Burenstam-Linder, S., 1961, An Essay on Trade and Transformation, Almqvist and Wiksells, Uppsala.

.Dosi, G., K. Pavitt and L. Soete, 1990, The Economics of Technical Change and International Trade, Harvester Wheatsheaf, New York

Durkin, J.T. and M. Krygier, 2000, Differences in GDP Per Capita and the Share of Intra-industry Trade: The Role of Vertically Differentiated Trade, Review of International Economics, 8, 760-774.

Eaton, J. and H.Kierzkowski ,1984, Oligopolistic Competition, Product Variety and International Trade, in H. Kierzkowski (ed.), Monopolistic Competition and International Trade, Oxford University Press, Oxford

Falvey, R., 1981, Commercial Policy and Intra Industry Trade, Journal of International Economics, 11, 495-511.

Flam, H. and E. Helpman, 1987, Vertical Product Differentiation and North-South Trade, American Economic Review, 77, 810-822.

Findlay, R. and C. Rodriguez, 1977, Intermediate Imports and Macroeconomic Policy Under Flexible Exchange Rates, Canadian Journal of Economics, 10, 208-17.

Goldstein, M. and M. Khan, 1985, Income and Price Effects in Foreign Trade, in R. Jones and P. Kenen (eds.) Handbook of International Economics, Volume 3, Elsevier, North-Holland.

Greenaway, D. and Torstenson, 1998, Economic Geography, Comparative Advantage and Trade Within Industries: Evidence from the OECD, CEPR Discussion Paper, No. 1857.

Greenaway, D., Hine, R.C. and C.R. Milner, 1995, Vertical and Horizontal IntraIndustry Trade: A Cross-Industry Analysis for the United Kingdom, Economic Journal, 105, 1505-1519.

Hausman, J.A., 1978, Specification Tests in Econometrics, Econometrica, 43, 727753.

Hooper, P. and J. Marquez, 1995, "Exchange Rates, Prices, and External Adjustment in the United States and Japan", in P. Kenen (ed.), Understanding Interdependence, Princeton University Press, Princeton, NJ. 
Krugman, P.R., 1995, What do we Need to Know about the International Monetary System? In P. Kenen (ed.), Understanding Interdependence, Princeton University Press, Princeton, NJ.

Markusen, J.R., 1986, Explaining the Volume of Trade: An Eclectic Approach, American Economic Review, 76, 1002-1011.

Pagan, A., 1984, Econometric Issues in the Analysis of Regressions with Generated Regressors, International Economic Review, 25, 221-247.

Pudney, S.E., 1982, The Identification of Rational Expectations Models Under Structural Neutrality, Journal of Economic Dynamics and Control, 4, 117-121.

Schmid, N., 1976, A Model of Trade in Money, Goods and Factors, Journal of International Economics, 7, 347-361.

Shaked, A. and J.Sutton, 1984, Natural Oligopolies and International Trade, in H. Kierzkowski (ed.), Imperfect Competition and International Trade, Oxford University Press, Oxford.

Stokey, N. L., 1991, The Volume and Composition of Trade Between Rich and Poor Countries, Review of Economic Studies, 58, 63-80.

\section{Data Appendix}

The trade data that we employ in this study is from the CHELEM (Harmonized Data for International Trade and the World Economy): Detailed Nomenclatures and Indicators database, July 1997. This data has been collected from various international sources and has been harmonized by the CEPII (Centre D'Études Prospectives Et D'Informations Internationales, Paris). The remaining data is from the OECD Statistical Compendium 1998(2).

$\underline{\text { Variable Definition }}$

C Competitiveness, relative consumer prices, $1991=100$

$E \quad$ Nominal bilateral exchange rate with the dollar Yen/\$

$M_{i} \quad$ Real imports, $M_{i}=\left(M N_{i} \cdot E\right) / M_{P}$

$M N_{i} \quad$ Nominal imports by commodity, $\$$

$M_{P} \quad$ Import price deflator, $1990=100$

$P \quad$ Index of Productivity, 1991=100

$W \quad$ Real total compensation per employee, $1991=100$

$Y \quad$ Real GDP, 1990 prices $\underline{\text { Source }}$

OECD Economic Outlook

CHELEM

transformation

CHELEM

OECD Economic Outlook OECD Economic Outlook OECD Economic Outlook OECD National Accounts 